\title{
Strategies to address challenging behaviour in young children with Down syndrome
}

\author{
Kathleen Feeley ${ }^{1}$ and Emily Jones ${ }^{2}$
}

Children with Down syndrome are at an increased risk for engaging in challenging behaviour that may present problems within community, leisure, and educational settings, and, in many instances, precludes them from accessing these environments. Factors contributing to the occurrence of challenging behaviours include characteristics associated with the Down syndrome behavioural phenotype, increased incidence of illness and sleep disorders, and the way in which individuals in their environment respond to their behaviours. In this paper we describe the use of behaviourally based intervention strategies to address some of the specific challenges often seen in young children with Down syndrome. Through a series of case studies, the effectiveness of evidence-based interventions addressing challenging behaviour is demonstrated.

(1) Department of Special Education and Literacy, C.W. Post Campus of Long Island University, 720 Northern Boulevard, Brookville, New York 11548, USA

(2) Department of Psychology, C.W. Post Campus of Long Island University, 720 Northern Boulevard, Brookville, New York 11548, USA

Correspondence to Dr. Kathleen Feeley•e-mail: kathleen.feeley@ liu.edu

doi:10.3104/case-studies.2008

() 2007 The Authors. Journal Compilation @ 2008 Down

Syndrome Education International.
At increasing rates, children with Down syndrome are being provided with the same life experiences as their non-disabled peers. More children with Down syndrome are fully integrated into the activities of their family and, in many communities, it is commonplace for children with Down syndrome to be integral members of their schools, neighbourhoods, and workplaces. However, for many children with Down syndrome (as is the case with other disabilities as well), success in these environments is hindered by challenging behaviour, defined by Doss and Reichle as behaviour that results "...in self-injury or injury of others, causes damage to the physical environment, interferes with the acquisition of new skills, and/or socially isolates the learner"(REF 1, p.215).

For many parents, researchers, and practitioners familiar with children with Down syndrome, challenging behaviour is a common occurrence. Children with Down syndrome are often described as "stubborn" and "obstinate." In fact, references to challenging behaviour have historically been seen in the clinical literature and continue to exist today. For example, children with Down syndrome show higher rates (than typically developing children) of attention problems, social withdrawal, noncompliance, and compulsions (such as arranging objects and repeating certain actions) $^{[2,3]}$, as well as high rates of selftalk ${ }^{[4]}$. With increasing age, behaviours associated with anxiety, depression, and withdrawal also increase ${ }^{[5]}$. Finally, recent research has indicated a pervasive pattern in children with Down syndrome, present from infancy, of escape and attention motivated challenging behaviours involving noncompliance and misuse of social behaviours $^{[6,7]}$.

The early onset and distinct presence of challenging behaviour has resulted in its inclusion as part of the behavioural phenotype (i.e., a unique pattern of strengths and weaknesses) that characterises Down syndrome ${ }^{[8]}$. Several other factors, specific to children with Down syndrome, including sleep disorders ${ }^{[9,10]}$ and increased incidence of illness ${ }^{[11]}$, may also increase the likelihood of challenging behaviour in children with Down syndrome ${ }^{[12]}$.

Fortunately, substantial empirical research demonstrates the effective use of behaviourally based procedures to assess and intervene on challenging behaviour in individuals with developmental disabilities (across the ages). However, close examination of the behavioural intervention literature reveals relatively few applications with children with Down syndrome and even fewer applications targeting the specific and characteristic challenges presented by these children. Over the past several years, we have successfully utilised behaviourally based intervention procedures to address challenging behaviour in young children with Down syndrome. In all instances, we substantially reduced the extent to which the children engaged in targeted challenging 
behaviour, resulting in enhanced performance in inclusive settings.

To illustrate the use of behaviourally based interventions with children with Down syndrome, we selected five case examples that reflect commonly occurring challenging behaviours among children with Down syndrome. The cases are categorised according to the type of intervention strategy. Specifically, intervention strategies addressing setting events and immediate antecedents, teaching replacement skills (e.g., communication, academic, social), and/or utilising consequence strategies (e.g., reinforcement) are illustrated. The reader is referred to Carr et al. ${ }^{[13]}$, Feeley and Jones ${ }^{[12]}$, and Reichle and Wacker ${ }^{[14]}$ for more complete discussions of intervention strategies. It is important to note that for each of these case examples, functional assessments were conducted prior to the start of intervention. A functional assessment involves the identification of setting events, antecedents, and consequences associated with the occurrence of challenging behaviour resulting in a hypothesised function regarding the maintaining consequences for that challenging behaviour. The reader is referred to O'Neill, Horner, Albin, Storey and Sprague ${ }^{[15]}$ for a description of functional assessment procedures.

\section{Strategies to address setting events}

Events occurring more distally in time from the occurrence of challenging behaviour, or not directly related to the immediate antecedents or consequences of challenging behaviour, can affect its likelihood of occurring ${ }^{[16-18]}$. Such variables have been referred to as both motivating operations ${ }^{[17]}$ and setting events ${ }^{[18]}$ and are described as events that occur "... at one point in time[that] may change the likelihood of a targeted behaviour at a later point in time by momentarily altering the value of consequences" (REF 19, p.382). Examples of such events that are likely to influence behaviour include a change in schedule, illness (e.g., allergies, virus), and sleep problems ${ }^{[20,21]}$. For children with Down syndrome, it is particularly important to consider setting events, because at least some known setting events such as sleep problems ${ }^{[9]}$ and illnesses ${ }^{[11]}$, occur at higher rates in children with Down syndrome, and are, therefore, likely to influence the occurrence of challenging behaviour ${ }^{[22]}$.

Interventions can be designed to specifically address setting events. To begin, it is important to establish that a relationship exists between the setting event and the child's engagement in challenging behaviour, by, for example, recording both the occurrence of the setting event(s) of concern and the child's behaviour. Consider a particular child whose challenging behaviour may be directly associated with the onset of an illness. The child's caregivers note the extent to which the child experiences symptoms of a specific illness (e.g., runny nose, fatigue, loose bowel movements) and then, they, as well as other caregivers (e.g., educators), note the occurrence of challenging behaviour. A relationship between challenging behaviour and a setting event is suggested if higher frequencies of challenging behaviour occur on the day/time(s) when the symptoms of illness were present.

Once it has been determined that a relationship exists between the setting event and challenging behaviour, a mechanism for caregivers to share with other caregivers (e.g., school personnel) when a child has experienced a particular setting event (e.g., lack of sleep, missed meal, parent away on a business trip) can be developed. A checklist, note, or regular phone call between caregivers can be used to communicate the occurrence setting event(s). This allows for the consideration of several interventions designed to ameliorate the effects of the specific setting event ${ }^{[20,23]}$. For example, in the presence of the setting event (e.g., day on which the symptoms of an illness start to become apparent), corresponding interventions may be implemented, including decreasing the likelihood of antecedents that trigger challenging behaviour and delivering higher rates of reinforcement. Both of these strategies were used with Nathan in his kindergarten class.

\section{Nathan}

Nathan was a 5 year old boy with Down syndrome enrolled in a general education kindergarten class. In addition to Nathan rising very early in the morning (often just after 5:00 a.m.), he was the third of four children in a family that had a very busy lifestyle (e.g., frequent visits to extended family, attendance at numerous athletic events of older siblings). Nathan's classroom staff began to notice that, on some days, Nathan appeared tired and had a tendency to engage in challenging behaviour (e.g., noncompliance, pushing educational materials away). Subsequently, they recorded the occurrence of Nathan's challenging behaviour. At this point, Nathan's parents were asked to place a note in his communication book (i.e., a small notebook dedicated to correspondence between the school staff and Nathan's parents) to indicate whether Nathan had a full night's sleep the previous evening. Within a short period of time, Nathan's classroom staff and parents were able to verify that noncompliant behaviour (i.e., refusal to respond to simple requests) occurred more often 


\section{Box 1 | An excerpt from Nathan's communication notebook prior to intervention}

9/26

Hi Ellen,

Nathan had a very difficult time in resource room today. He kept asking to go home (he didn't feel warm) and became very noncompliant after a simple request. Do you think Nathan was just a little off today? Or maybe something else?

Rachel

\section{Box 2 | Excerpts \\ from Nathan's communication notebook during intervention}

\section{0/8}

Hi Rachel,

Nathan didn't get much sleep last night. We were out late and he was up very early (5:00). We hope his (and your) day goes smoothly.

\section{Ellen}

\section{$10 / 8$}

Hi Ellen,

Thanks for the note. Nathan did seem tired early on, but he had a great day. While in resource room, we played the matching game. Have a nice afternoon.

Rachel during academic tasks (e.g., letter identification, counting) on days when Nathan did not get enough sleep the evening prior.

\section{Intervention}

Nathan's education team implemented a package intervention to address the setting event, lack of sleep. Nathan's parents continued to either write a note in the communication book or phone the school with a message for Nathan's teaching assistant indicating when Nathan did not get enough sleep. On the days Nathan did not sleep enough, the classroom staff decreased academic demands and increased access to highly preferred activities. Specifically, Nathan's teachers asked him to complete fewer tasks within academic activities, while at the same time they increased opportunities to play "games" in which instructional targets were incorporated. For example, instead of completing a workbook page of counting tasks, Nathan was engaged in a table top bowling game during which he counted the number of pins. This allowed his interventionist to continue to work on academic skills, however, because it was done within an activity that was highly preferred, Nathan did not engage in challenging behaviour. Additionally, interacting with Nathan in this manner (fewer task demands and increased access to preferred activities) resulted in Nathan receiving an increased rate of reinforcement. Thus, there were many more opportunities for staff to praise (i.e., verbally or with a high five or handshake) than would have been typically delivered had these specific strategies not been in place.

Nathan's parents and teachers continued to document in his home-school communication notebook the occurrence of disruptions in sleep and challenging behaviour. BOX 1 depicts an excerpt of anecdotal information when setting event intervention strategies were not implemented. As illustrated in the note from Nathan's' teaching assistant (Rachel) to Nathan's mother (Ellen), Nathan had a very difficult day. On this day, Nathan had not slept well the night before, however school staff were not informed, and intervention strategies to prevent challenging behaviour were not implemented. BOX 2 depicts Nathan's mother (Ellen) alerting Nathan's teaching assistant to the fact that he had not slept well the night before. After receiving the note that Nathan did not sleep enough the night before, Nathan's teaching assistant (Rachel) indicates they played a matching game instead of engaging in the typical academic demands (antecedents for challenging behaviour when Nathan had not slept well). As well, Nathan had a "great day." Because of their effectiveness, Nathan's classroom staff continued to use these setting event intervention strategies throughout the remainder of the school year noting that they resulted in substantial improvement in Nathan's behaviour.

\section{Additional applications}

There are some events, such as sleep disorders and illnesses, that have a high incidence of occurrence in children with Down syndrome, and therefore, should be given careful consideration when addressing challenging behaviours. In addition, there may be very individualised setting events (e.g., death in the family, transition to new school) that increase the likelihood of challenging behaviour in specific children. Thus, both of these types of setting events should be carefully monitored.

When setting events occur outside of the school setting, as happened with Nathan, communication between home and school is an important component of effective intervention. However, caregivers may not be in a position to report such events. Although this presents a particular challenge, interventionists can begin to look for precursor behaviours that may be associated with the occurrence of the setting event and challenging behaviour. For example, if Nathan's parents were not able to regularly communicate about his sleep patterns, interventionists might look for signs of insufficient sleep when he arrives at school (e.g., dark circles under Nathan's eyes, slouching in his seat on the school bus). Additionally, if the child has sufficient communication skills, upon arrival at school he/she can be asked about the occurrence of the setting event (e.g., "Did you sleep well last night?" "What time did you wake this morning?"). If the child's communication skills are limited, interventionists may develop graphic representations of setting events to communicate their occurrence (e.g., a photo or drawing depicting a person who is overly tired).

\section{Antecedent based strategies}

Similar to setting event intervention strategies, antecedent intervention strategies ${ }^{[24]}$ are implemented prior to the occurrence of challenging behaviour in an effort to decrease the likelihood that challenging behaviour will occur. To implement antecedent based strategies, a functional behaviour assessment should be implemented in which the challenging behaviour and associated environmental events (both antecedents and consequences) are documented. That is, throughout the time period of concern (e.g., academic lesson, transition from one place to another, at home during mealtime), data are recorded, including the activity and specific events that occurred just prior to the occurrence of challenging behaviour (e.g., type of request made, by whom, etc.). 
This information can reveal when the challenging behaviour is likely to occur. For example, on several occasions, following a request (antecedent) to put his belongings (e.g., lunch box, jacket) in the coat closet, Tim refused and dropped his belongings to the floor (behaviour), resulting in his teacher putting them away for him (consequence). Each day, when another child, Meredith, was asked to clean up after snack (antecedent), she responded by crying (behaviour), which resulted in her classmates cleaning up for her (consequence). Thus, a functional assessment reveals a pattern of particular antecedents (e.g., requests) that reliably predict specific challenging behaviours (e.g., noncompliance, dropping to the floor, crying).

Once the specific antecedents associated with challenging behaviour have been identified, several strategies can be implemented just prior to the delivery of the antecedent, preventing challenging behaviour from occurring. The research literature has demonstrated the effective use of a number of antecedent strategies ${ }^{[24]}$, two of which were used with Cody in his preschool.

\section{Cody}

Cody was a 3 year 10 month old boy with Down syndrome who attended a preschool programme where he received a combination of intensive instruction and participation in an integrated preschool class in which half of the children had mild disabilities and half were typically developing. In his preschool class, Cody had a tendency to engage in challenging behaviour that consisted of refusal to comply with teacher requests (i.e., ignoring the requests and dropping to the floor). A functional assessment revealed Cody engaged in noncompliant behaviour often accompanied with dropping to the floor when his teachers requested that he transition from one activity to another (i.e., the antecedent). In many instances, following engagement in the challenging behaviour, Cody ultimately avoided transitioning to the next activity.

\section{Intervention}

Cody's education team chose to implement two different antecedent interventions prior to requesting that Cody transition. One of the interventions, prespecified reinforcer ${ }^{[25]}$, involves informing the child what she/he will receive upon completion of a specific task (in this case, the transition). For Cody, the reinforcing items (e.g., computer games, stickers, crayons, and bubbles) were chosen based upon the specific transition. For example, Cody consistently engaged in challenging behaviour when asked to come in from the playground. As a result, one of his favourite activities in his classroom, playing on the com-

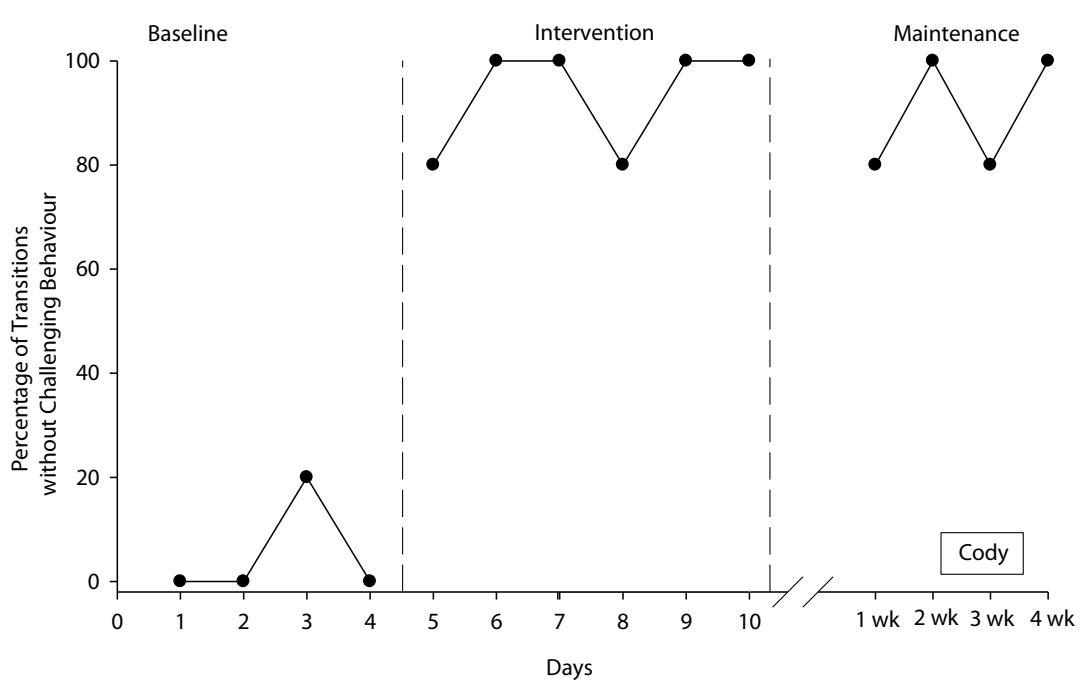

Figure 1 | Percentage of transitions during which Cody did not display challenging behaviour.

puter, was prespecified prior to requesting him to enter the school (e.g., "Cody, we have your favourite game all ready for you to play on the computer. Quick let's get on line and go inside so you can take a turn.”).

Another intervention, preferred item/activity as a distractor, involves offering the child a preferred item to distract him/her from the aversiveness of the request ${ }^{[26]}$. For example, when transitioning between locations within the classroom, Cody's teacher asked him to carry supplies (the preferred item) from one instructional centre to the other. When transitioning between rooms, Cody's teacher asked him to be the "Whistle Blower" (i.e., the student who blows the class whistle in order to gain the students' attention). The use of either the prespecified reinforcer or preferred item as distracter strategy was at the teachers' discretion and was typically based on the availability of preferred items to serve as distracting stimuli during the transition.

The effect of these intervention strategies on Cody's challenging behaviour is illustrated in FIGURE 1. Data were recorded during five specific transitions both within and outside of his classroom each day (i.e., moving from free time in the classroom to group lessons, between three different centres within the classroom, and from the playground to the classroom). During baseline, Cody complied with only $0-20 \%$ of transitions. During intervention, compliance increased to $80-100 \%$ of transitions. Over time, Cody's classroom staff were able to fade the use of the interventions, resulting in Cody complying with requests to transition (in the absence of any intervention techniques) without engaging in challenging behaviour (labelled Maintenance in FIGURE 1). 


\section{Additional applications}

Prespecified reinforcer and preferred item as distractor are only two of several different antecedent strategies, including choice, high probability request sequence, and offer of collaboration. Choice involves presenting the child with options prior to the presentation of the antecedent event that triggers challenging behaviour (e.g. REFS 2729). For Cody, his teachers could have provided him with a choice of centres (e.g." "Would you like to go to the drawing centre or the counting centre?") when presenting the request to transition (the antecedent) to centre time. Another antecedent strategy that could have been applied by Cody's team is that of a high probability request sequence, in which the interventionist delivers a series of requests to which the child is highly likely to comply (each followed by the delivery of reinforcement) followed by a request to which the child has a low probability of responding (e.g. REFS 19,30,31). To illustrate, Cody's teacher could have asked him to complete several acts he could easily and readily perform (e.g., "Touch your nose," "Show me a thumbs up," and "Give me five") each followed by the delivery of verbal praise (e.g., "Great job Cody") and then delivered the low probability request (i.e., the request to transition, such as "Let's go to the counting centre."). An offer of collaboration entails the interventionist offering to collaborate with the child on the task which is likely to trigger challenging behaviour ${ }^{[25]}$. For example, when transitioning between centres, instead of saying, "Turn off the computer and go to the counting centre," the teacher might say, "Let's press the off button together so we can go to the counting centre."

It is important to note that antecedent strategies are most effective when used prior to the occurrence of challenging behaviour. Too often caregivers and interventionists "forget" to use the antecedent intervention until after the challenging behaviour occurs. Therefore, in order to prevent the challenging behaviour from occurring, one should remember to use them proactively, that is, prior to delivering the antecedent that is likely to trigger the challenging behaviour.

\section{Skill building strategies}

In many instances, challenging behaviour is related to the child's limited repertoire of more acceptable responses and, often, these responses are communicative in nature. For example, a child may not have the expressive language to request a break, thus, he/she may throw materials as a means of indicating he/she is finished with the activity. A child may not have an appropriate means to get a teacher's attention, thus, he/she may fidget in his/her chair so staff in the class- room will stand in close proximity. These examples illustrate instances in which children do not have a communicative response to get what they want and, thus, could benefit from being taught a replacement response (i.e., a new skill such as signing for "break" or tapping a teacher's shoul$\operatorname{der})^{[13,32]}$.

In other situations, children may have appropriate communicative responses in their repertoire, but use them in situations where they are not appropriate. For example, in some situations, such as when a family member arrives at a child's house, it is appropriate for the child to greet them with a big hug. In other situations, such as when a delivery person arrives at the child's house with pizza, it is appropriate to say "Hello" and perhaps shake the person's hand, but it would be inappropriate to give the pizza delivery person a big hug. These subtle discriminations may prove difficult for children with Down syndrome. Not only do these situations require discrimination skills, they also require a large repertoire of social behaviours on the part of the child that include multiple forms of greetings (e.g., a high five, wave, and handshake), that they can use in place of an affectionate greeting (e.g., hug).

Importantly, it is not the specific response (in this case, an affectionate greeting) that is challenging, but the context in which it occurs that may make it problematic. Therefore, it is important that children with Down syndrome be systematically taught not only to discriminate when certain behaviours should be emitted, but also alternative responses so they are prepared to respond in various situations. The following case study illustrates the instruction of a greeting (i.e., handshake) to replace Michael's hugging of strangers.

\section{Michael}

Michael was a 4 year old boy with Down syndrome attending a preschool programme where he spent part of his day receiving intensive instruction and part of his day in a community preschool. Michael's family was concerned about his propensity to greet unfamiliar adult males by hugging them, both in public (e.g., patients in doctors' offices) and in his home (e.g., pizza delivery person). Michael's mother recorded his greeting behaviour in the presence of unfamiliar males in two settings: in the home when delivery person arrived and in the community (e.g., doctor's office, restaurants).

\section{Intervention}

To expand upon Michael's greeting repertoire, he was taught to shake hands. Initially, Michael was taught to shake hands with individuals with whom he was familiar, within his preschool 
programme. Intervention took place within a discrete trial format (i.e., the presentation of multiple teacher directed instructional opportunities in close temporal proximity, with the use of specific prompts, followed by the delivery of reinforcing consequences) ${ }^{[33]}$. During intervention, a familiar adult entered Michael's instructional area, at which point his teaching assistant prompted Michael to shake hands by saying, "Michael, shake [name's] hand." When Michael responded by shaking the hand of the familiar adult, reinforcement (e.g., high five, verbal praise) was delivered. Any incorrect response (e.g., attempting to hug or climb in the adult's lap) was immediately interrupted, and Michael was physically prompted to shake hands. At least 10 intervention opportunities were conducted per school day until Michael's performance met criterion for mastery (i.e., shook the familiar adult's hand during $80 \%$ or more of the opportunities on a given day without physical prompting).

After Michael's performance met this criterion, intervention was conducted while taking walks throughout the preschool setting rather than just within his classroom. Upon approaching a familiar male (e.g., male teacher in Michael's programme, familiar parent of another child), his teaching assistant delivered the verbal prompt, "There's [name]. Michael, shake his hand." Between 3 and 5 intervention opportunities were conducted at least three days per week. Correct responses were reinforced. Incorrect responses were interrupted and Michael was physically prompted to shake hands.

Once Michael's performance met criterion (i.e., shook the familiar adult's hand on walks in his preschool on $80 \%$ or more of the opportunities without physical prompting), intervention opportunities involved unfamiliar males. Michael's teacher and teacher's assistants set up situations within the preschool in which unfamiliar males (e.g., fathers of children unfamiliar to Michael, staff who worked in other programmes within the building or who were visiting from other buildings) approached Michael and his teaching assistant. Prompting, reinforcement, and correction procedures were delivered in the same manner as during prior intervention. Due to the planning involved in these teaching opportunities, only 3-5 opportunities were provided each week. Mom reported that after intervention, Michael appropriately greeted both familiar and unfamiliar individuals at home and within his community.

\section{Additional applications}

There is a perception on the part of many people that children with Down syndrome are affectionate and loving. It has also been hypothesised that

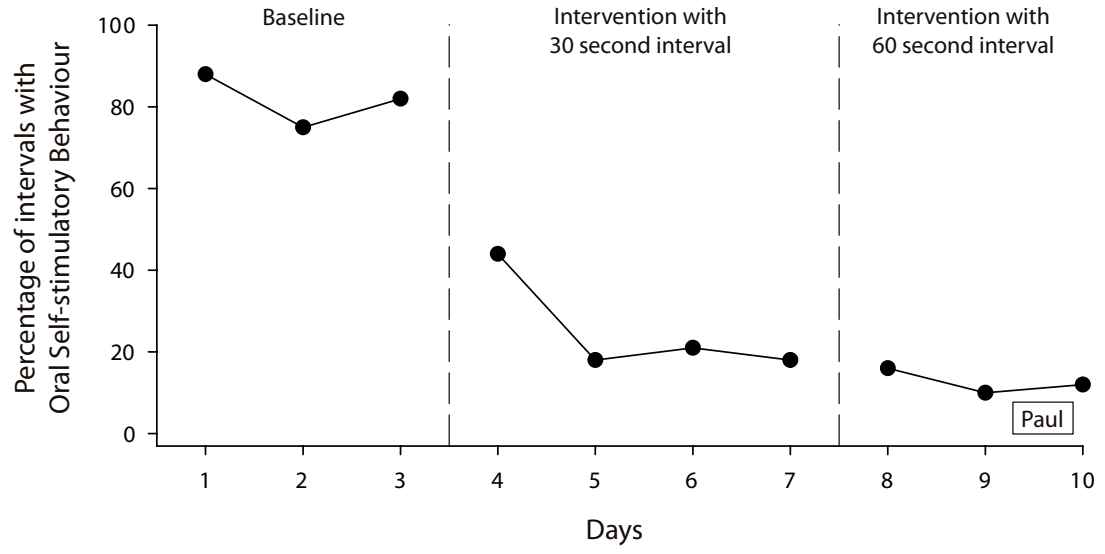

Figure 2 | Percentage of intervals during which Paul displayed oral selfstimulatory behaviour.

others respond differently to children with Down syndrome and their affectionate behaviour. Clinically, we have seen some children with Down syndrome treated differently than their peers without disabilities, such that they are permitted and encouraged to engage in affectionate behaviour that would be unacceptable from a typically developing child of the same chronological age. For example, in several educational settings, we have observed classroom staff requesting hugs from the children with Down syndrome or permitting children with Down syndrome to sit on their laps, yet these interactions did not occur with the typically developing children within the same setting. Although endearing, it is very important that children with Down syndrome be treated in a similar fashion to their non-disabled peers. Thus, not only is it important to teach children with Down syndrome appropriate behaviours in corresponding situations from an early age, but to address this differential treatment on the part of adults in their environment.

Not being taught when to refrain from engaging in certain displays of affection may also negatively affect the child's relationships with their peers. Same age peers of children with Down syndrome may not always respond well to affectionate approaches. At first, a peer may respond by saying "Move back" or "Don't hug me." If the child with Down syndrome persists, a peer may become angry and/or begin to avoid interacting with the child with Down syndrome. Therefore, specific instruction in appropriate ways to greet peers as well as how to respond to requests made by those peers is important. Finally, identifying and teaching those responses that are socially acceptable within each child's social circle (e.g., high five, thumbs up, fancy handshake) will likely prove beneficial for the child with Down syndrome. 


\section{Consequence based strategies}

Once an antecedent associated with challenging behaviour has occurred, a child may either engage in the challenging behaviour or refrain from engaging in that challenging behaviour. The consequence delivered by the caregiver and/ or interventionist at this juncture impacts how the child responds in the future. In past research, to decrease challenging behaviour, interventionists relied heavily on consequence strategies implemented after the challenging behaviour occurred (i.e., punishment procedures). Alternatively, interventionists can rely on positive consequence strategies, implemented when the challenging behaviour is not emitted. That is, the antecedent occurs and, if the child refrains from engaging in challenging behaviour, specific consequences are delivered that increase the likelihood the child will refrain from emitting the challenging behaviour in the future. This type of consequence strategy is termed differential reinforcement.

Differential reinforcement procedures include the use of reinforcement following the occurrence of an alternative appropriate behaviour (DRA), emitted in place of the challenging behaviour ${ }^{[34]}$ and the use of reinforcement following the omission of the behaviour (DRO). The following case studies illustrate the use of differential reinforcement procedures to address escape motivated behaviour in Sam and self-stimulatory behaviour in Paul.

\section{A strategy to address escape motivated behaviour}

Given the high rates of escape motivated challenging behaviour present even in young children with Down syndrome, it is often necessary to incorporate consequence procedures so the child can benefit from educational experiences. One easily implemented application of differential reinforcement of alternative behaviour (DRA) is within a token system. A token system involves the use of a symbol or token delivered as a consequence for appropriate behaviour that can be traded for backup reinforcers ${ }^{[35,36]}$. As illustrated in our case example of Sam, the use of a token system can begin at a very young age.

\section{Sam}

Sam was 2 years 6 months old and was receiving early intervention services within his home. In addition to receiving physical, speech, and occupational therapy on a weekly basis, Sam received two 45 minute sessions of intervention implemented by a special educator. During these sessions, his interventionist addressed expressive and receptive communication, as well as play skills (i.e., turning the page of a book, activating buttons to play music, engaging in multi-step play sequences). During intervention sessions, Sam had a tendency to engage in behaviour that his interventionist and mother believed interfered with his acquisition of skills. During intervention activities, Sam refused to respond to the interventionist by turning away from her, covered his face, and/or threw the instructional materials (i.e., toys, pictures), resulting in avoidance of some of his intervention activities.

\section{Intervention}

Sam's education team decided to implement a token reinforcement system during these intervention sessions. This involved the delivery of tokens following appropriate responses (i.e., imitating speech sounds, pointing to common objects, and imitating play behaviours) that could
Strategies to address setting events - Setting event checklist - Decrease presence of antecedents - Increase available reinforcement
Positive Behaviour Support Plan
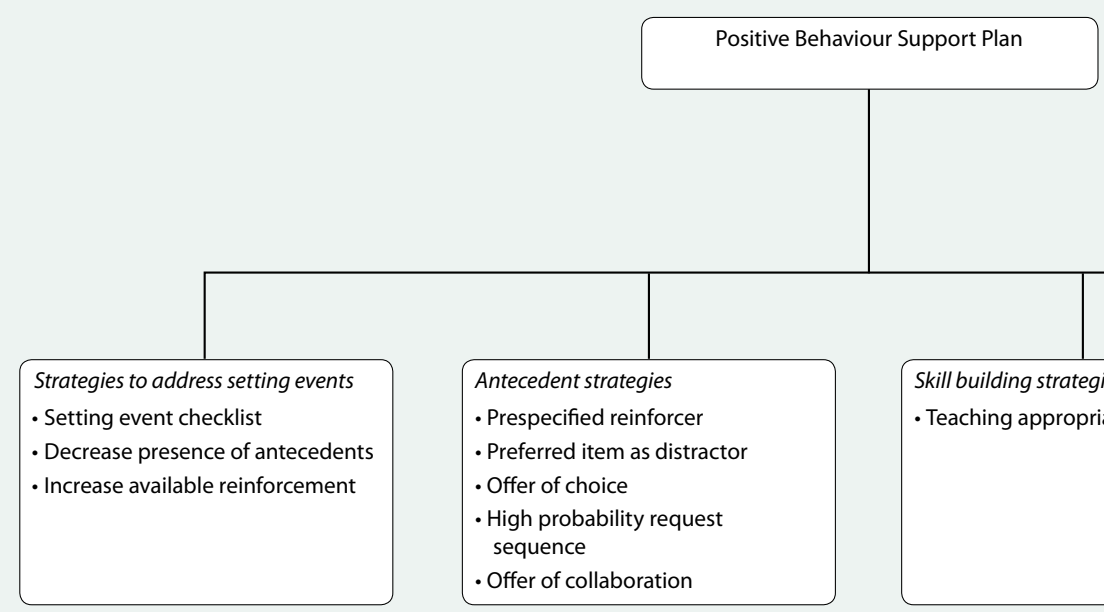

Skill building strategies

- Teaching appropriate social skills

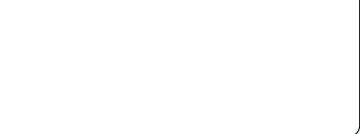

Consequence strategies

- Differential reinforcement of the omission of behaviour - Token systems

Figure 3 | Components of a Positive Behaviour Support Plan with example interventions illustrated by each of the case studies presented. 
be traded for a backup reinforcer (e.g., access to a favourite book). Sam's team chose small pictures $\left(4 \mathrm{~cm}\right.$ by $4 \mathrm{~cm}$ ) of Blue's Clues ${ }^{\mathrm{TM}}$ characters as tokens and, after laminating them, attached the tokens to a board with Velcro ${ }^{\mathrm{TM}}$. Sam's mother identified several preferred items that could be used as backup reinforcers (e.g., favourite books) and his interventionist often brought toys (e.g., electronic toys, barn and animals) that also functioned as reinforcers for other target behaviours. Initially, the goal was for Sam to earn three tokens before trading them in for access to one of his backup reinforcers. At the beginning of intervention, two tokens were placed on the board. An instruction was given to Sam (e.g., "Show me the [object name]" during receptive object identification tasks) and, as soon as Sam responded appropriately, the last of the three tokens was placed on the board. Sam's interventionist delivered verbal reinforcement (e.g., "That was terrific!") and then provided him with access to the back up reinforcer (e.g., reading him a few pages from a book). Across teaching opportunities, Sam's interventionist began with fewer Blue's Clues ${ }^{\mathrm{TM}}$ tokens (i.e., one and then zero) attached to the board at the start of the intervention session so that Sam had to respond to more teaching opportunities (i.e., two and then three teaching opportunities) prior to receiving access to his reinforcer. As Sam's challenging behaviour decreased, the number of tokens Sam was required to earn (and hence the number of teaching opportunities implemented) before receiving his back up reinforcer was increased from three to five.

The concern of Sam's mother and his interventionists was that Sam's noncompliance interfered with his acquisition of skills because it decreased the number of teaching opportunities that could be provided when so much time was spent dealing with challenging behaviour. With the token system in place, Sam's intervention sessions were more productive with an increase in number of intervention opportunities and less time spent dealing with Sam's challenging behaviour. Additionally, with increased intervention opportunities, Sam began to master skills at a faster rate. The use of the token system therefore resulted in Sam remaining on task for more intervention opportunities and spending less time engaging in challenging behaviour.

\section{Additional applications}

Token systems have been used extensively to address the performance of a variety of behaviours in individuals with and without disabilities. Tokens can take multiple forms. For example, they can be preferred pictures, as with Sam, whose tokens were pictures of a favourite character. In the case of a child who has difficulty attending during story time and whose backup reinforcer is colouring, the individual crayons can act as tokens. For example, for each 3 minute time period of attending during story time, a crayon (i.e., token) can be discretely placed in a box. Once the child has remained on task for the determined amount of time (e.g., 15 minutes), the box of crayons (i.e., backup reinforcer) can be given to the child for him to use. Tokens can also consist of the puzzle pieces of a picture of the backup reinforcer. In this situation, once the picture of the backup reinforcers is complete (i.e., all the pieces or tokens have been earned), the backup reinforcer itself is provided.

Another consideration with token systems is the criterion for earning the backup reinforcer. It is important to set the criterion at a point the child can achieve. For example, the child may be required to earn only 4 of the 5 possible tokens to receive his/her backup reinforcer. The use of a token system can be gradually faded, such that tokens are delivered intermittently, rather than for each occurrence of a target behaviour. For example, a child may be earning tokens for appropriately transitioning between activities. Instead of having to successfully transition on one occasion to earn each token, fading the token system might involve requiring the child to transition twice before earning a token. As the child is successful, the number of transitions can be further increased (to three, four, etc.). Eventually, the expectations might be that if all transitions are successful for the day, a token is delivered and then traded in at the end of the week.

Tokens can often be delivered in a discreet manner, an important consideration when children are in inclusive environments. Children can even learn to deliver their own tokens (called self-management) (e.g. REF 37) increasing the discreetness of the token system. For example, a child can place checkmarks (tokens) on a paper in his notebook during classroom lessons. The child may eventually be taught to judge when he/ she has reached criteria for earning tokens and access his/her backup reinforcer with little adult intervention.

\section{A strategy to address self- stimulatory behaviour}

Although children with Down syndrome tend to engage in high rates of escape and attention motivated challenging behaviour, there are other challenging behaviours whose function is often related to pleasurable sensory feedback (i.e., self-stimulatory behaviour), that can become particularly problematic. Engaging in self-stimulatory behaviour may decrease a child's engage- 
ment with the environment resulting in valuable learning opportunities being missed. Additionally, self-stimulatory behaviour may result in social isolation. For example, the child may be ostracised by his peers for such behaviours (e.g., putting his hand in his mouth, making peculiar noises, or using objects/toys in an unconventional manner [e.g., waving a toy car in front of his/her eyes]).

Differential reinforcement of the omission of behaviour (DRO) is often used as a consequence strategy to address self-stimulatory behaviour (e.g. REF 38). DRO involves systematically delivering reinforcement following a specified interval of time during which the target behaviour is not emitted $^{[34]}$. DRO was used with Paul to address an oral self-stimulatory behaviour.

\section{Paul}

Paul was a 3 year old boy with Down syndrome who attended a preschool programme in which he received intensive intervention for 2.5 hours each morning. In the afternoon, he attended an integrated preschool class in which half of the children had mild disabilities and half were typically developing. Paul engaged in a challenging behaviour that took the form of tongue protrusion while at the same time making a "clicking" noise. This behaviour was stigmatising, disruptive, and often precluded Paul from attending during group lessons. Paul engaged in this behaviour for $75-88 \%$ of the time he was observed during a series of his daily activities within his preschool. A functional assessment indicated this behaviour served a self-stimulatory function, that is, Paul engaged in the behaviour in the presence or absence of other individuals and the behaviour did not result in any external reinforcers (e.g., attention, access to preferred items, or escape from a task).

\section{Intervention}

Paul's education team decided to implement a differential reinforcement programme in which he was not only reinforced for the absence of the behaviour (DRO), but a mild correction procedure was implemented when the behaviour did occur. DRO involved delivering reinforcement in the form of praise (e.g., "Wow, you look terrific Paul", "That's looking like a big boy Paul!") or physical interaction (e.g., high five) if Paul did not engage in the tongue protrusion and clicking during a specified time interval. The correction procedure consisted of Paul's teaching assistant placing her hand near (but not touching) his chin and saying, in a gentle voice, "uh, uh," if Paul engaged in tongue protrusion and clicking. This correction procedure was chosen because it immediately resulted in the cessation of the behaviour (while other correction procedures such as only saying "uh uh" did not have the same effect) and it was a procedure with which Paul's parents were comfortable having educational staff perform.

During baseline (i.e., prior to intervention), Paul's self-stimulatory behaviour occurred at such a high rate that a 30 second time interval was selected to begin intervention (30 seconds was the longest period of time that Paul would refrain from engaging in self-stimulatory behaviour). If Paul did not engage in tongue protrusion with clicking for 30 seconds, his teaching assistant delivered reinforcement in the form of verbal praise (e.g., "Wow, you're a handsome guy", "You look terrific," and/or physical interaction, such as rubbing his arm or giving him a high five). If the behaviour did occur, Paul's teaching assistant immediately placed her hand near his chin and, in a quiet voice said, "uh uh," and Paul did not receive reinforcement for that 30 second interval.

As Paul's tongue clicking behaviour decreased when reinforcement was delivered at 30 second intervals, the interval was increased to $60 \mathrm{sec}$ onds. Reinforcement was eventually completely faded during all classroom activities, with one exception. Paul's team noticed the only time Paul continued to engage in the tongue protrusion behaviour was during difficult fine motor tasks (e.g., cutting, stringing beads). It was during these time periods only, that his teachers continued to deliver specific reinforcement for the omission of his self-stimulatory behaviour.

FIGURE 2 displays Paul's progress. During baseline Paul engaged in this behaviour for $75-88 \%$ of the time he was observed. Within a week of starting intervention, Paul was successfully participating in all classroom activities (with the exception of fine motor activities) with very low levels (10-16\% of 60 second intervals) of the self-stimulatory behaviour. Thus, the rigorous implementation of differential reinforcement intervention resulted in a decrease in Paul's challenging behaviour to the extent that it was no longer a concern of his parents or the any of the members of his educational team.

\section{Additional applications}

Self-stimulatory behaviours can take several forms, including oral behaviours such as that in which Paul engaged (e.g., tongue clicking, lip licking, mouthing objects), whole body behaviours (e.g., rocking), and inappropriate manipulation of objects (e.g., repeatedly shaking a toy car). Differential reinforcement procedures have been successfully applied resulting in decreases in such behaviours to a level at which they are no longer considered a problem (either very low 
rates of occurrence or no occurrences). While Paul's intervention involved a differential reinforcement of other behaviour (DRO), other differential reinforcement procedures such as those that identify a specific alternative or incompatible behaviour to reinforce (instead of the challenging behaviour) may also be successfully applied. For example, if a child engages in a self-stimulatory behaviour using objects in his/her environment, he/she can be systematically reinforced for engaging in the appropriate action. Writing with a pen or marker can be reinforced as an incompatible behaviour with chewing on the end of the writing instrument. Decreasing self-stimulatory behaviours is particularly important as the presence of such behaviours often interferes with learning and leads to further social isolation or stigmatisation of a child with Down syndrome.

\section{Conclusion}

Each of these cases was chosen to illustrate the use of evidence-based intervention procedures that effectively decreased challenging behaviours in children with Down syndrome. First, each case example illustrates the application of a specific intervention strategy. However, individual intervention strategies such as those described here are often applied in combination as a package positive behaviour support plan (e.g. REF. 13). Positive behaviour support plans consist of intervention strategies combined to address setting events, antecedents, skill building, and consequences related to challenging behaviour. Consider a child who engages in escape motivated challenging behaviour during morning circle and is more likely to do so on days when his allergies are bothering him. A positive behaviour support plan might include increasing reinforcement during circle time on days when he shows signs of allergy (e.g., red runny nose) (i.e., setting event strategy), and presenting him with a preferred item as distractor during that activity (e.g., having the child hold the book while the teacher reads) (i.e., antecedent strategy). The child could also be systematically taught to ask to leave circle time (rather than engaging in challenging behaviour to escape circle time) (i.e., skill building) and his interventionists could deliver specific consequences for appropriate circle time behaviour (e.g., token system) (i.e., consequence strategy). The effectiveness of individual intervention strategies as illustrated in these case examples suggests the use of combined intervention packages for children with Down syndrome will be similarly effective. FIGURE 3 illustrates the four components of a positive behaviour support plan and intervention strategies illustrated in the previous case examples.

Second, the case examples were chosen to specifically reflect some of the significant factors (e.g., sleep problems, escape motivated behaviour) associated with challenging behaviour in children with Down syndrome. Continued research is warranted to examine additional applications of behaviourally based intervention procedures to address the specific characteristics associated with Down syndrome. The early onset of escape and attention seeking challenging behaviour ${ }^{[6,7]}$ has been included in the behavioural phenotype that characterises Down syndrome ${ }^{[8]}$. The early demonstration of such challenging behaviour can significantly and negatively impact outcomes for children with Down syndrome. Therefore, developing effective intervention strategies that can be used from a very young age, such as the token system with Sam, is imperative to circumvent the negative outcomes associated with such early behaviours. In fact, as families and professionals become well versed in effective intervention strategies, intervention can be implemented automatically so that significant challenging behaviour never enters the child's repertoire.

Finally, in these case examples the presence of challenging behaviour significantly impacted the children's access to and success in typical environments (e.g., general education classroom, Doctor's office). The decrease in challenging behaviour as a result of the use of behaviourally based intervention strategies led to increased successful opportunities to participate in typical environments. Thus, the application of evidencebased assessment and intervention strategies to address challenging behaviour in children with Down syndrome is important to ensure successful inclusion in community settings without risk of removal based on challenging behaviour. 
1. Doss S, Reichle J. Replacing excess behavior with an initial communicative repertoire. In Reichle J, York J and Sigafoos J, editors. Implementing augmentative and alternative communication strategies for learners with severe disabilities. Baltimore, MD: Paul H. Brookes; 1991: p.215-237.

2. Coe DA, Matson JL, Russell DW, Slifer KJ, Capone GT, Baglio C, Stallings S. Behavior problems of children with Down syndrome and life events. Journal of Autism and Developmental Disorders. 1999; 39: 149-156.

3. Evans DW, Gray FL. Compulsive-like behavior in individuals with Down syndrome: Its relation to mental age level, adaptive and maladaptive behavior. Child Development. 2000; 71: 288-300.

4. Glenn SM, Cunningham CC. Parents' reports of young people with Down syndrome talking out loud to themselves. Mental Retardation. 2000; 38: 498-505.

5. Dykens EM, Kasari C. Maladaptive behavior in children with Prader-Willi syndrome, Down syndrome, and nonspecific mental retardation. American Journal on Mental Retardation. 1997; 102: 228-237.

6. Wishart J. The development of learning difficulties in children with Down's syndrome. Journal of Intellectual Disability Research. 1993; 37: 389-403.

7. Wishart J. Learning the hard way: Avoidance strategies in young children with Down's syndrome. Down Syndrome Research and Practice. 1993; 1: 47-55.

8. Fidler DJ. The emerging Down syndrome behavioral phenotype in early childhood: Implications for practice. Infants and Young Children. 2005; 18 : 86-103.

9. Stores R. A preliminary study of sleep disorders and daytime behavior problems in children with Down's syndrome. Down Syndrome Research and Practice. 1993; 1: 29-33.

10. Stores R, Stores G. Research on sleep problems and psychological function in children with Down syndrome: Implication for clinical practice and everyday care. Down Syndrome Research and Practice. 1996; 4: 110-112.

11. Roizen NJ. Down syndrome and associated medical disorders. Mental Retardation and Developmental Disability Research Reviews. 1996; 2: 85-89.

12. Feeley KM, Jones EA. Addressing challenging behaviour in children with Down syndrome: The use of applied behaviour analysis for assessment and intervention. Down Syndrome Research and Practice. 2006; 11: 64-77.

13. Carr EG, Levin L, McConnachie G, Carlson Jl, Kemp DC, Smith C. Communication based intervention for problem behavior: A user's guide for producing positive change. Baltimore, MD: Paul H. Brookes; 1994.

14. Reichle J, Wacker D, editors. Communicative alternatives to challenging behavior: Integrating functional assessment and intervention strategies. Baltimore: Paul H. Brookes; 1993.

15. O'Neill RE, Horner RH, Albin RW, Storey K, Sprague JR. Functional assessment and program development for problem behavior: A practical handbook. $2^{\text {nd }}$ ed. Pacific Grove, CA: Brooks/Cole; 1997.

16. Michael J. Distinguishing between discriminative and motivational functions of stimuli. Journal of the Experimental Analysis of Behavior. 1982; 37: $149-155$

17. Michael J. Implications and refinements of the establishing operation concept. Journal of Applied Behavior Analysis. 2000; 33: 401-410.

18. Wahler RG, Fox JJ. Setting events in applied behavior analysis: Toward a conceptual and methodological expansion. Journal of Applied behavior Analysis. 1981; 14: 327-338.

19. Horner R, Day M, Sprague J, O'Brien M, Heathfield L. Interspersed requests: A nonaversive procedure for reducing aggression and self-injury during instruction. Journal of Applied Behavior Analysis. 1991; 24: 265-278.

20. Dadson S, Horner RH. Manipulating setting events to decrease problem behavior: A case study. Teaching Exceptional Children. 1993; 25: 53-55.

21. McGill P, Teer K, Rye L, Hughes D. Staff reports of setting events associated with challenging behavior. Behavior Modification. 2005; 28: 599615.

22. Richdale A, Francis A, Gavidia-Payne S, Cotton S. Stress, behavior, and sleep problems in children with an intellectual disability. Journal of Intellectual and Developmental Disability. 2000; 25 147-161.

23. Horner RH, Vaughn BJ, Day HM, Ard WR. The relationship between setting events and problem behavior: expanding our understanding of heavier support. In Koegel LK and Dunlap $\mathrm{G}$, editors. Positive behavioral support including people with difficult behavior in the community. Baltimore, MD: Paul H. Brooks; 1996: p.381-402.

24. Kern L, Choutka CM, Sokol NG. Assessmentbased interventions used in natural settings to reduce challenging behaviors: A review of the literature. Education and Treatment of Children. 2002; 25: 113-134.

25. Davis C, McEvoy M, Reichle J. Minnesota Behavioral Support Project; 2005[cited Apr 14, 2006]. Available from: http://education.umn.edu/ceed/projects/preschoolbehavior/strategies/mbsp.pdf

26. Davis CA, Reichle JE, Southard KL. High-probability requests and preferred items as a distractor: Increasing successful transitions in children with behavior problems. Education and Treatment of Children. 2000; 23: 423-440.

27. Bambara LM, Koger F, Katzer T, Davenport TA. Embedding choice in the context of daily routines: An experimental case study. Journal of the Association for Persons with Severe Handicaps. 1995; 20:15-195.

28. Dunlap G, DePerczel M, Clarke S, Wilson D, Wright S, White R, Gomez A. Choice making to promote adaptive behavior for students with emotional and behavioral challenges. Journal of Applied Behavior Analysis. 1994; 27: 505-518.

29. Dyer K, Dunlap G, Winterling V. Effects of choice making on the serious problem behaviors of students with severe handicaps. Journal of Applied Behavior Analysis. 1990; 23: 515-524.

30. Davis CA, Brady MP, Williams RE, Hamilton R. Effects of high-probability requests on the acquisition and generalization of responses to requests in young children with behavior disorders. Journal of Applied Behavior Analysis. 1992; 25: 905-916.

31. Mace FC, Belfiore P. Behavioral momentum in the treatment of escape-motivated stereotypy. Journal of Applied Behavior Analysis. 1990; 23: 507-514.

32. Durand VM, Carr EG. Functional communication training to reduce challenging behavior: Maintenance and application in new settings. Journal of Applied Behavior Analysis. 1991; 24: 251-264.

33. Lovaas OI. Behavioral treatment and normal educational functioning in young autistic children. Journal of Consulting and Clinical Psychology. 1987; 55: 3-9.

34. Cooper JO, Heward TE, Heron WL. Applied behavior analysis. Upper Saddle River, NJ: Merril; 1987.

35. Dalton AJ, Rubino CA, Hislop MW. Some effects of token rewards on school achievement of children with Down's syndrome. Journal of Applied Behavior Analysis. 1973; 6: 251-259.

36. Johnston JM, Johnston GJ. Modification of consonant speech sound articulation in young children. Journal of Applied Behavior Analysis. 1972; 5: 233-246.

37. Broden M, Hall RV, Mitts B. The effect of selfrecording on the classroom behavior of two eighth-grade students. Journal of Applied Behavior Analysis. 1971; 4: 191-199.

38. Repp AC, Deitz SM, Speir NC. Reducing stereotypic responding of retarded persons by differential reinforcement of other behavior. American Journal of Mental Deficiency. 1974; 79: 279-284.

\section{Acknowledgements}

We would like to acknowledge the children and families who participated in these case studies, as well as the professionals (teachers and teaching assistants), who implemented the procedures.

Received: 21 September 2006; Accepted 14 February 2007; Published online: 6 August 2007. 